\title{
Air toxics and early childhood acute lymphocytic leukemia in Texas, a population based case control study
}

\author{
Elaine Symanski ${ }^{* *}$, P. Grace Tee Lewis ${ }^{1}$, Ting-Yu Chen², Wenyaw Chan², Dejian Lai ${ }^{2}$ and Xiaomei Ma ${ }^{3}$
}

\begin{abstract}
Background: Traffic exhaust, refineries and industrial facilities are major sources of air toxics identified by the U.S. Environmental Protection Agency (U.S. EPA) for their potential risk to human health. In utero and early life exposures to air toxics such as benzene and 1,3-butadiene, which are known leukemogens in adults, may play an etiologic role in childhood leukemia that comprises the majority of pediatric cancers. We conducted a population based case-control study to examine individual effects of benzene, 1,3-butadiene and polycyclic organic matter (POM) in ambient residential air on acute lymphocytic leukemia (ALL) diagnosed in children under age 5 years in Texas from 1995-2011.

Methods: Texas Cancer Registry cases were linked to birth records and then were frequency matched by birth month and year to 10 population-based controls. Maternal and infant characteristics from birth certificates were abstracted to obtain information about potential confounders. Modelled estimates of benzene, 1,3-butadiene and POM exposures at the census tract level were assigned by linking geocoded maternal addresses from birth certificates to U.S. EPA National-Scale Air Toxics Assessment data for single and co-pollutant statistical analyses. Mixed-effects logistic regression models were applied to evaluate associations between air toxics and childhood leukemia.
\end{abstract}

Results: In adjusted single pollutant models, odds of childhood leukemia among mothers with the highest ambient air exposures compared to those in the lowest quartile were 1.11 (95\% Cl: 0.94-1.32) for POM, 1.17 (95\% Cl: 0.98-1.39) for benzene and 1.29 (95\% Cl: 1.08-1.52) for 1,3-butadiene. In co-pollutant models, odds ratios for childhood leukemia remained elevated for 1,3-butadiene but were close to the null value for benzene and POM.

Conclusions: We observed positive associations between 1,3-butadiene and childhood leukemia in single and co-pollutant models whereas effect estimates from single pollutant models were diminished for benzene and POM in co-pollutant models. Early life exposure to 1,3-butadiene rather than benzene or POM appears to increase early childhood risk of acute lymphocytic leukemia.

Keywords: Air toxics, Benzene, 1,3-Butadiene, Polycyclic organic matter, POM, Childhood leukemia, Epidemiology, Acute lymphocytic leukemia, Childhood cancer

\footnotetext{
* Correspondence: Elaine.Symanski@uth.tmc.edu

${ }^{1}$ Department of Epidemiology, Human Genetics and Environmental Sciences,

University of Texas Health Science Center at Houston School of Public

Health, Houston, Texas, USA

Full list of author information is available at the end of the article
}

\section{Ciömed Central}

(C) 2016 The Author(s). Open Access This article is distributed under the terms of the Creative Commons Attribution 4.0 International License (http://creativecommons.org/licenses/by/4.0/), which permits unrestricted use, distribution, and reproduction in any medium, provided you give appropriate credit to the original author(s) and the source, provide a link to the Creative Commons license, and indicate if changes were made. The Creative Commons Public Domain Dedication waiver (http://creativecommons.org/publicdomain/zero/1.0/) applies to the data made available in this article, unless otherwise stated. 


\section{Background}

Leukemia is the most common pediatric cancer in the United States (U.S.) [1]. About $80 \%$ of childhood leukemias are acute lymphocytic leukemia (ALL) with approximately 2,200 new cases of ALL diagnosed annually in children under 15 years in the United States [2]. Most childhood ALL is diagnosed between ages 2 and 5 years with higher rates for males than females and for Hispanics and whites as compared to blacks [3]. In Texas, leukemia also leads childhood cancers and accounted for $32.2 \%$ of cases in children $0-14$ years from 2007-2011 [4]. Among Texas children 0-4 years, there are on average 119 new ALL diagnosed annually [5].

Aside from ionizing radiation and specific genetic disorders [6-9], the etiology of childhood leukemia, which likely varies by subtype [10], remains largely unknown. There has been growing interest in identifying environmental risk factors that may play a role in pathogenesis and one focus has been on air toxics. Air toxics, also known as hazardous air pollutants, were first identified in 1990 by the U.S. Environmental Protection Agency (EPA) because of concerns about their impact on human health [11]. Emissions from industrial facilities, refineries and power plants, as well as automotive exhaust, are major sources of air toxics [12-15]. Of particular interest are benzene and 1,3-butadiene that are known leukaemogens in adults $[11,16,17]$. Additionally, we focused on polycyclic organic matter (POM) representing a broad range of organic compounds comprised of two to seven fused aromatic rings of which polycyclic aromatic hydrocarbons (PAHs) are the most common subclass $[18,19]$.

Relatively few investigations of associations between benzene, 1,3-butadiene or PAHs and childhood cancer risk have been conducted and findings have been equivocal. For benzene, six population-based case control studies and one ecologic study have evaluated the association with childhood leukemia [20-25]. Two population based case control studies, one in Italy and the other in California, reported positive associations with estimated relative risks that ranged from 1.50 to 3.91 among children with high benzene exposure [20, 21]. An ecologic study in Texas likewise observed higher odds of childhood leukemia in census tracts with upper quartile ambient benzene levels $(\mathrm{OR}=1.37,95 \% \mathrm{CI}$ : $1.05,1.78)$ [25]. Four case control studies conducted in Europe, on the other hand, observed null associations [22-24, 26]. Among these investigations, the study populations included children diagnosed at different ages, namely, less than 19 years of age [25], less than 15 years of age $[20,22-24,26]$ and less than 5 years of age [21, 24]. Despite its established carcinogenicity in adults [16], 1,3-butadiene studies in children are rare. Two US studies, one a case-control study and the other an ecologic study, have assessed the role of 1,3-butadiene relative to childhood leukemia risk. For children aged 19 years or younger at diagnosis in Southeast Texas who lived in census tracts with the highest 1,3-butadiene levels, elevated rate ratios were detected for all leukemias and ALL [25]. In a more recent investigation of Californian children diagnosed under the age of six years, Heck et al. found elevated odds for both ALL and acute myeloid leukemia (AML) [21]. Among the three population based case-control investigations of PAHs and leukemia risk $[21,27,28]$ that also varied in diagnosis ages of children who comprised the study populations, two found positive associations [21, 27] and one reported no association [28]. All were conducted in the US and used modeled or measured estimates of PAH exposures [21, 27, 28].

Owing to the scarcity of studies that have examined a possible etiologic role of air toxics in early childhood leukemia and building on our earlier ecologic investigation of children of all ages [25], we designed a case-control study to examine the hypothesis that risk for ALL among children diagnosed under the age of five increases with exposure to benzene, 1,3-butadiene and PAHs in utero and in infancy. This study uses data from one of the largest population-based cancer registries in the U.S., links registry data to birth certificates to obtain information on maternal and infant characteristics and assesses both single and co-pollutant models of three air toxics that are known carcinogens in adults.

\section{Methods}

The study protocol was approved by the Institutional Review Boards at the University of Texas Health Science Center at Houston and the Texas Department of State Health Services (TX DSHS).

\section{Study population}

We obtained incident cases of ALL and AML diagnosed from January 1, 1995 to October 31, 2011 from the Texas Cancer Registry. Our study population was limited to children diagnosed under age 5 years regardless of race or ethnicity. We used the Surveillance, Epidemiology and End Results Program (SEER) recode of the International Classification of Diseases for Oncology, 3rd Edition (ICD-O-3), World Health Organization (WHO) 2008 codes (2/9/2001 update) by histology type to define ALL (codes: 9826, 9835-9837) and AML (codes: 9840, 9861, 9865-9867, 9869, 9871-9874, 9891, 98959897, 9898, 9910-9911, 9920) cases. Only cases with birth records that could be linked to the Texas Cancer Registry were eligible for inclusion. Controls were sampled from TX DSHS vital statistics birth records from 1991 to 2009. A 10:1 matching ratio was used to select controls based on birth year and month to allow for the 
same potential for exposures to air toxics. For all birth records, geocoded addresses of maternal residence at delivery were obtained and records were linked to the TX DSHS Birth Defects Registry to identify infants with congenital anomalies. In total, 1,741 leukemia cases and 17,410 population based controls were identified. We excluded 2,025 birth records with missing geocoding data, 428 non-singleton births and 119 infants born with one or more birth defects. After applying exclusion criteria, 16,579 observations remained. Based on statistical power implications and number of AML $(n=170)$ in our study population, we restricted analysis to ALL cases $(n=1,248)$ and matched controls $(n=12,172)$.

\section{Exposure assessment}

Our exposure assessment for benzene, 1-3, butadiene and PAHs was based on maternal address at delivery and relied upon data from the U.S. EPA National-Scale Air Toxics Assessment (NATA) [29]. NATA provides modeled estimates of air toxics in specific years (1996, 1999, 2002 and 2005) for all census tracts in the continental US, Puerto Rico and the Virgin Islands using the Assessment System for Population Exposure Nationwide (ASPEN). ASPEN uses annual National Toxic Inventory emission data of hazardous air pollutants from major (point) source, area, monitoring, and emissions as inputs in modelling exposures levels. Emissions from background and mobile sources are also estimated and combined with other inputs to produce census tract level HAP modelled estimates [30]. The ASPEN model accounts for the rate, location and height of release of pollutants, wind speed and direction, reactive decay, deposition and secondary formation or decay [30, 31]. Data on benzene, 1,3-butadiene and POM (or PAHPOM as per NATA 2002 and 2005) are available in all NATA releases [18]. POM defines a broad class of compounds that includes the PAHs. We used total POM in our analysis rather than a POM subset of PAHs due to inconsistent availability of PAH groups across NATA data releases [32]. Total POM is available in all NATA years whereas modelled estimates of PAHs are only available in the 1996 and 1999 releases [32]. A map illustrating NATA estimated ambient air levels of 1,3-butadiene for all Texas census tracts corresponding to the release years used in our study is given in Fig. 1. Maps for benzene and POM are available as supplemental figures [see Additional file 1: Figures S1 and Additional file 2: Figure S2, respectively]. Geocoded addresses from birth certificates for infants born in 1991-1997, 1998-2000, 2001-2003 and 2004-2011 were linked to the 1996, 1999, 2002 and 2005 NATA data, respectively.

\section{Covariates}

We abstracted maternal and infant characteristics from birth certificates to evaluate as potential confounders, including maternal age at the time of child's birth (years), marital status (married, not married) and trimester prenatal care started (first, second, or third). Maternal race and ethnicity were categorized as: white, nonHispanic; black, non-Hispanic; Hispanic; other. Because the TX DSHS updated birth certificates in 2005, we standardized coding for maternal smoking during pregnancy (yes/no) and educational level (elementary: 0-6th grade, before high school: 7-11th grade, high school: 12th grade, Associate's degree and Bachelor's degree and higher). Birth weight (grams), sex and length of gestation (full term, 37 completed weeks or more of gestation; mildly preterm, 32-36 weeks gestation; and severely preterm, $<32$ weeks gestation) were also evaluated as confounders. Finally, based on the U.S. 2000 Census, percent of people living below the poverty level was assessed as a potential neighborhood-level covariate in the analyses [33].

\section{Statistical methods \\ Single and co-pollutant models}

Mixed-effects logistic regression models were applied to evaluate the associations between air toxics and childhood leukemia using PROC GLIMMIX in SAS statistical software (version 9.3, SAS Inc., Cary, NC). Air pollutants were modeled categorically using the distribution among the controls for each NATA year to define quartile cut points (low, medium, medium-high and high). The lowest quartile was the referent category. For each air pollutant, we ran models adjusting for the matching factors $[34,35]$ (infant's birth year and month) and a random effect for census tract (hereafter referred to as Model 1). To evaluate confounding, each potential covariate was added to Model 1 and the percentage of change in the magnitude of the odds ratio for each air pollutant was calculated between models. While none of the covariates selected for analysis changed the estimated odds ratios by $10 \%$ or more [36], we further applied a backward model selection method with a significance level set at 0.05 to account for the potential for joint confounding and obtained the final regression equation. Six observations were dropped from models due to missing maternal age and infant birth weight. For all three air toxics, we obtained a model that included mother's age and race/ethnicity and infant's birth weight and gender (hereafter referred to as Model 2). We also included two air toxics together in co-pollutant models (benzene and 1,3-butadiene; benzene and POM; 1,3 butadiene and POM) and assessed potential confounding effects of these three pollutants by comparing to the results from the single pollutant models. 


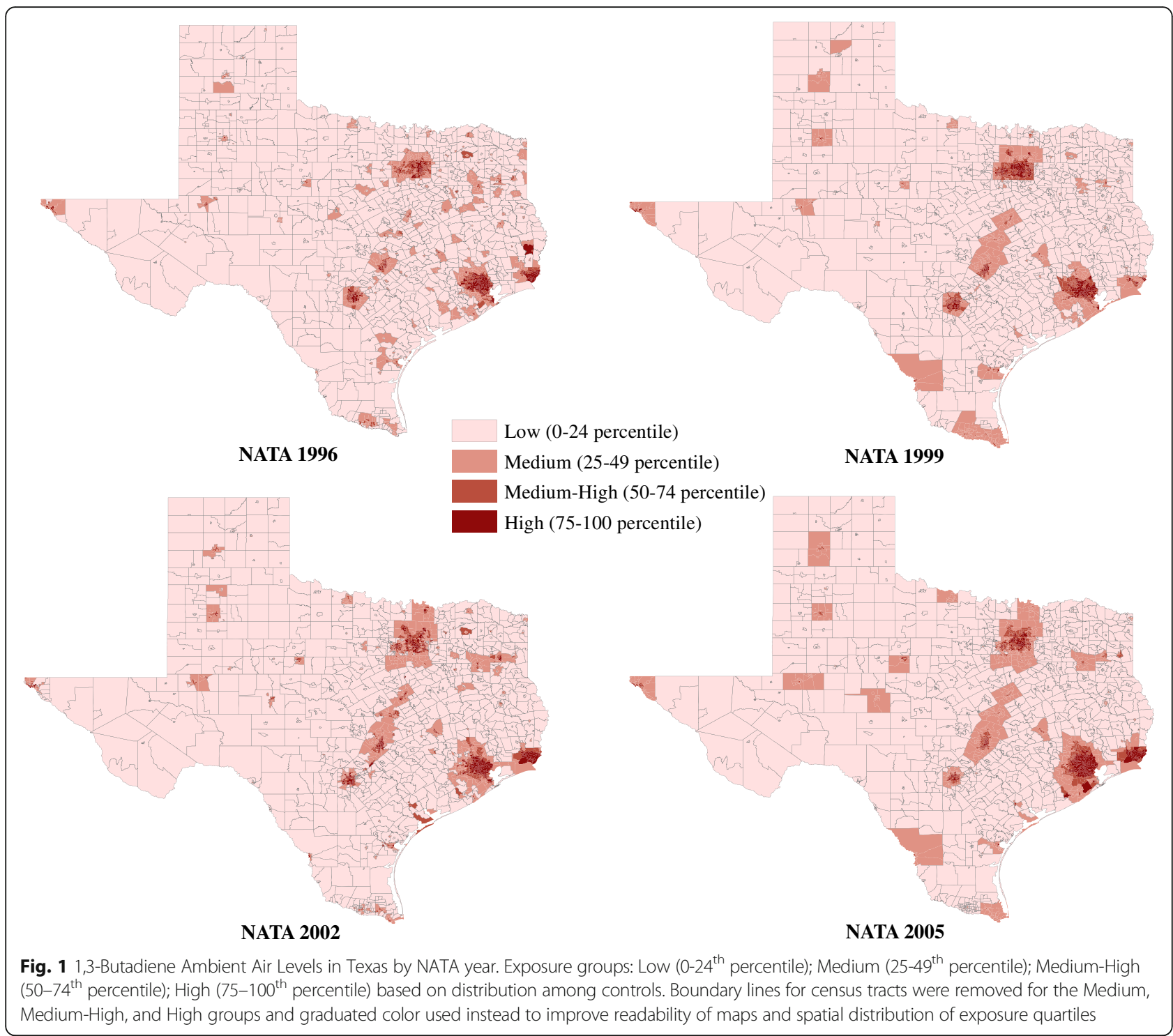

\section{Correlations and collinearity diagnostics}

Correlations between categorical rankings of pollutants were evaluated using Spearman's rank correlation coefficient: $\rho=0.81$ for benzene and 1,3-butadiene; $\rho$ $=0.74$ for benzene and POM; and $\rho=0.75$ for $1,3-\mathrm{bu}-$ tadiene and POM). Given the extent of correlation using quartile exposure groupings, we performed additional diagnostics for collinearity [37]. We used PROC GENMOD in SAS to generate information matrices and weights for the information matrices. Using these outputs for model iterations, we applied SAS PROC REG with VIF and COLLIN options to assess collinearity and found no evidence of collinearity in categorical forms of our exposure variables. VIF values in our collinearity diagnostics ranged from 4.0 to 5.5 and well below VIF $\geq 10.0$ rule of thumb [38]. Further, conditional index numbers were all less than
4.0 and well below the cut point of 30 indicative of potential collinearity [38].

\section{Sensitivity analyses}

We conducted a sensitivity analysis limiting our study population to births within a year before or after the NATA data release year: 1996 (1995-1997 births), 1999 (1998-2000 births), 2002 (2001-2003 births), and 2005 (2004-2006 births). Further, recognizing possible spatial correlations of residuals, we also conducted a sensitivity analysis exploring a different error structure for single pollutant models using SAS Proc GLIMMIX to account for exponential spatial correlation. We deleted 167 records with duplicate longitude and latitude coordinates and assumed the spatial correlations were constrained within year and month to address computational constraints. We found little differences in the point 
estimates and standard errors in comparing results to the mixed effects models (with census tract specified as a random effect) and, hence, report on results using the more parsimonious model.

\section{Results}

Maternal and infant characteristics of the study population at the time of delivery appear in Table 1. Most mothers were married, did not smoke cigarettes during pregnancy and lived in neighborhoods with poverty rates under $20 \%$. Based on results of crude logistic regression models for each maternal or infant characteristic, there were differences at delivery in maternal age, marital status, and race/ethnicity, infant birth weight and gender for cases as compared to controls.

Selected percentiles of the distributions of residential benzene, 1,3-butadiene and POM levels $\left(\mu \mathrm{g} / \mathrm{m}^{3}\right)$ in control subjects, by NATA year, are shown in Fig. 2 . Benzene had the highest concentration levels across all years as compared to 1,3-butadiene and POM. The mean ( \pm standard deviation (SD)) concentration of benzene in 1996 was $0.89( \pm 0.68) \mu \mathrm{g} / \mathrm{m}^{3}, 1.40( \pm 0.78) \mu \mathrm{g} / \mathrm{m}^{3}$ in 1999, $1.30( \pm 0.66) \mu \mathrm{g} / \mathrm{m}^{3}$ in 2002 and $0.96( \pm 0.46) \mu \mathrm{g} /$ $\mathrm{m}^{3}$ in 2005. Mean levels of 1,3-butadiene were 0.08 $( \pm 0.18) \mu \mathrm{g} / \mathrm{m}^{3}, 0.13( \pm 0.11) \mu \mathrm{g} / \mathrm{m}^{3}, 0.09( \pm 0.12) \mu \mathrm{g} / \mathrm{m}^{3}$ and $0.06( \pm 0.05) \mu \mathrm{g} / \mathrm{m}^{3}$, in $1996,1999,2002$ and 2005 , respectively, while mean POM concentrations were $0.069( \pm 0.069) \mu \mathrm{g} / \mathrm{m}^{3}$ in $1995,0.008( \pm 0.007) \mu \mathrm{g} / \mathrm{m}^{3}$ in 1999, $0.008( \pm 0.006) \mu \mathrm{g} / \mathrm{m}^{3}$ in 2002 and $0.006( \pm 0.004)$ $\mu \mathrm{g} / \mathrm{m}^{3}$ in 2005.

Odds ratios (OR) and $95 \%$ confidence intervals (CI) for benzene, $1-3$, butadiene and POM in single pollutant models are given in Table 2. In the fully adjusted model (Model 2) for benzene, we found elevated odds for ALL

Table 1 Maternal and Infant Characteristics of Childhood Acute Lymphocytic Leukemia Cases and Controls at Birth in Texas, 19952011

\begin{tabular}{|c|c|c|c|}
\hline \multirow[t]{2}{*}{ Characteristic } & \multirow{2}{*}{$\begin{array}{c}\text { Cases } \\
N=1,248\end{array}$} & \multirow{2}{*}{$\begin{array}{c}\text { Controls } \\
N=12,172\end{array}$} & \multirow{2}{*}{$\begin{array}{c}\text { Crude OR } \\
(95 \% \mathrm{Cl})\end{array}$} \\
\hline & & & \\
\hline Maternal Age (years) (Mean (SD)) & $26.8(6.2)$ & $26.1(6.0)$ & $1.02(1.01,1.03)$ \\
\hline Birth weight (grams) (Mean (SD)) & $3411.6(525.1)$ & $3309.7(549.7)$ & $1.04^{b}(1.03,1.05)$ \\
\hline \multicolumn{4}{|l|}{ Infant Gender (\%) } \\
\hline Male & 55.5 & 52.0 & $1.15(1.02,1.30)$ \\
\hline Female & 44.5 & 48.0 & 1.00 \\
\hline \multicolumn{4}{|l|}{ Marital Status (\%) } \\
\hline Married & 70.4 & 66.9 & 1.00 \\
\hline Not Married & 29.6 & 33.0 & $0.85(0.75,0.97)$ \\
\hline \multicolumn{4}{|c|}{ Cigarette Smoking during Pregnancy (\%) } \\
\hline Yes & 5.4 & 6.0 & $0.89(0.68,1.15)$ \\
\hline No & 93.5 & 93.0 & 1.00 \\
\hline \multicolumn{4}{|c|}{ Percentage Living Below Poverty Level ${ }^{\complement}(\%)$} \\
\hline$<20 \%$ & 66.2 & 65.3 & 1.00 \\
\hline $20 \%$ & 33.8 & 34.7 & $0.96(0.85,1.08)$ \\
\hline \multicolumn{4}{|l|}{ Maternal Education ${ }^{\mathrm{d}}(\%)$} \\
\hline Elementary & 29.6 & 29.4 & $1.17(0.89,1.53)$ \\
\hline Before high school & 19.3 & 20.2 & $1.03(0.86,1.24)$ \\
\hline High school & 21.1 & 22.7 & 1.00 \\
\hline Associate degree & 14.3 & 12.7 & $1.21(0.99,1.48)$ \\
\hline Bachelor and graduate degree & 15.0 & 13.8 & $1.17(0.96,1.43)$ \\
\hline \multicolumn{4}{|l|}{ Maternal Race/Ethnicity (\%) } \\
\hline White, Non-Hispanic & 40.6 & 38.4 & 1.00 \\
\hline Black, Non-Hispanic & 5.5 & 12.4 & $0.41(0.32,0.54)$ \\
\hline Hispanic & 50.6 & 45.6 & $1.05(0.93,1.20)$ \\
\hline Other & 3.3 & 3.6 & $0.86(0.61,1.20)$ \\
\hline
\end{tabular}

${ }^{a}$ Estimates from mixed effects logistic regression model adjusted for the matching variables and census tract (random effect)

${ }^{\mathrm{b}}$ ORs reported per 100 gram increase in birth weight

'Based on maternal residence. Data source: USA Census 2000; www.census.gov

${ }^{\mathrm{d}}$ Highest level completed 

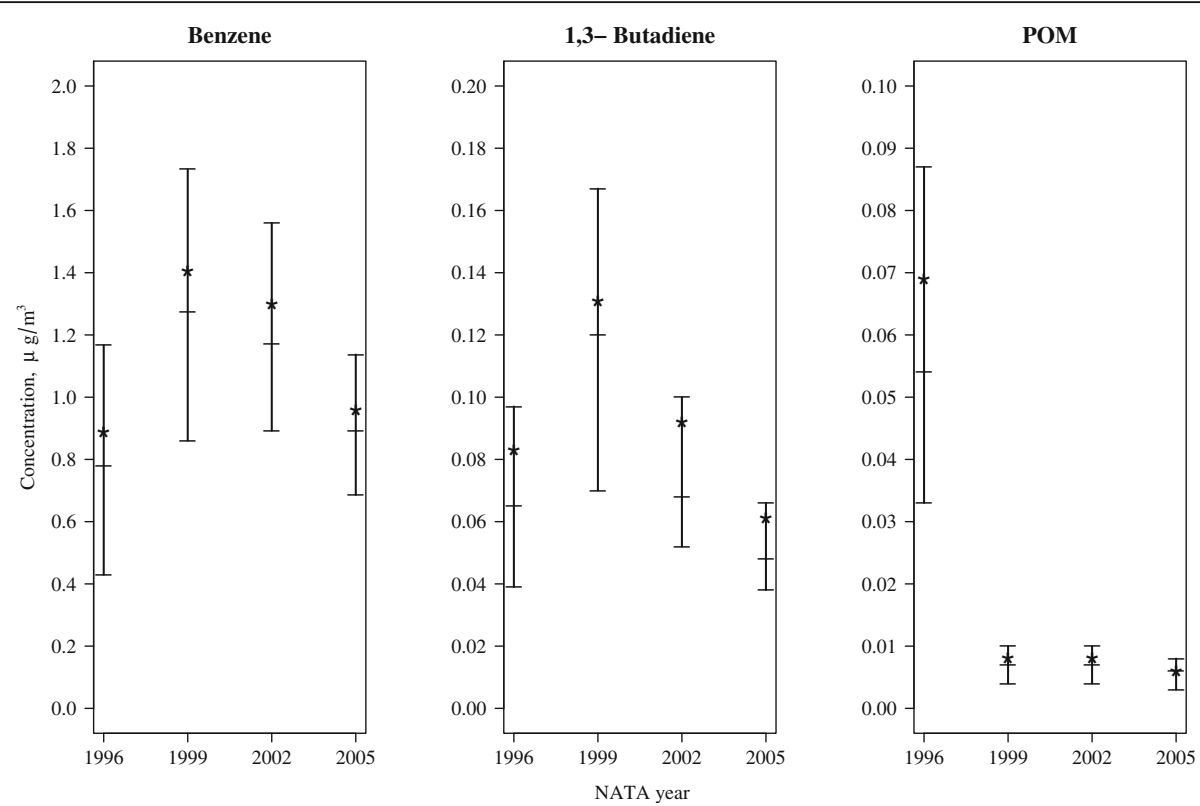

Fig. 2 Distribution of Benzene, 1,3-Butadiene, and Polycyclic Organic Matter (POM) for selected percentiles: $25 \%$, 50 \%, $75 \%$ by year for controls $(N=12,178)$, based on maternal address at birth, Texas. Mean denoted by *. Data source: National-Scale Air Toxics (NATA), U.S. Environmental Protection Agency. www.epa.gov/national-air-toxicsassessment

in the medium $(\mathrm{OR}=1.19 ; 95 \% \mathrm{CI}: 1.00-1.41)$, medium-high ( $\mathrm{OR}=1.16 ; 95 \% \mathrm{CI}: 0.98-1.38)$ and high exposure groups ( $\mathrm{OR}=1.17 ; 95 \% \mathrm{CI}: 0.98-1.39$ ) as compared to the referent group. For 1,3-butadiene, we observed odds ratios of 1.23 (95\% CI: 1.03-1.46), 1.23 (95 \% CI: 1.04-1.47) and 1.29 (95 \% CI: 1.08-1.52) for the medium, medium-high and high exposure groups, respectively. Albeit not statistically significant, we observed positive associations between ALL and POM for those in the medium-high $(\mathrm{OR}=1.18 ; 95 \% \mathrm{CI}: 1.00$ 1.39 ) and high exposure (OR $=1.11 ; 95 \%$ CI: 0.94-1.32) categories.

Results for the co-pollutant models appear in Table 3. In fully adjusted models that included benzene and 1,3-

Table 2 Association between Childhood Acute Lymphocytic Leukemia in Texas and Air Toxics: Benzene, 1,3-Butadiene, and Polycyclic Organic Matter using Single Pollutant Models

\begin{tabular}{|c|c|c|}
\hline Air Toxic & Model $1^{\text {a }}$ OR $(95 \% \mathrm{Cl})$ & Model $2^{\mathrm{b}}$ OR $(95 \% \mathrm{Cl})$ \\
\hline \multicolumn{3}{|l|}{ Benzene } \\
\hline Low & 1.00 & 1.00 \\
\hline Medium & $1.18(1.00,1.40)$ & $1.19(1.00,1.41)$ \\
\hline Med-High & $1.13(0.95,1.33)$ & $1.16(0.98,1.38)$ \\
\hline High & $1.14(0.96,1.35)$ & $1.17(0.98,1.39)$ \\
\hline \multicolumn{3}{|l|}{ 1,3-Butadiene } \\
\hline Low & 1.00 & 1.00 \\
\hline Medium & $1.21(1.02,1.43)$ & $1.23(1.03,1.46)$ \\
\hline Med-High & $1.18(0.99,1.40)$ & $1.23(1.04,1.47)$ \\
\hline High & $1.22(1.03,1.44)$ & $1.28(1.08,1.52)$ \\
\hline \multicolumn{3}{|c|}{ Polycyclic Organic Matter } \\
\hline Low & 1.00 & 1.00 \\
\hline Medium & $0.93(0.78,1.10)$ & $0.94(0.79,1.12)$ \\
\hline Med-High & $1.13(0.96,1.34)$ & $1.18(1.00,1.39)$ \\
\hline High & $1.07(0.91,1.27)$ & $1.11(0.94,1.32)$ \\
\hline
\end{tabular}

${ }^{a}$ Model 1 includes air pollutant exposure variables, matching variables and census tract (random effect). $N=13,420$

${ }^{\mathrm{b}}$ Model 2 includes variables from Model 1, as well as maternal age, infant birth weight (per 100 grams), infant gender and maternal race/ ethnicity. $N=13,420$ 
Table 3 Association between Air Toxics and Acute Lymphocytic Leukemia in Texas using Co-Pollutant Models

\begin{tabular}{|c|c|c|}
\hline Air Toxic & Model $1^{\mathrm{a}}$ OR $(95 \% \mathrm{Cl})$ & Model $2^{\mathrm{b}}$ OR (95\% Cl) \\
\hline \multicolumn{3}{|c|}{ Benzene and 1,3-Butadiene } \\
\hline \multicolumn{3}{|l|}{ Benzene } \\
\hline Low & 1.00 & 1.00 \\
\hline Medium & $1.06(0.87,1.30)$ & $1.07(0.87,1.31)$ \\
\hline Med-High & $0.96(0.75,1.22)$ & $0.95(0.75,1.22)$ \\
\hline High & $0.92(0.70,1.22)$ & $0.91(0.69,1.20)$ \\
\hline \multicolumn{3}{|l|}{ 1,3-Butadiene } \\
\hline Low & 1.00 & 1.00 \\
\hline Medium & $1.19(0.97,1.45)$ & $1.22(1.00,1.50)$ \\
\hline Med-High & $1.22(0.96,1.55)$ & $1.28(1.01,1.63)$ \\
\hline High & $1.32(1.00,1.74)$ & $1.40(1.06,1.86)$ \\
\hline \multicolumn{3}{|c|}{ 1,3-Butadiene and Polycyclic Organic Matter } \\
\hline \multicolumn{3}{|l|}{ 1,3-Butadiene } \\
\hline Low & 1.00 & 1.00 \\
\hline Medium & $1.25(1.04,1.50)$ & $1.26(1.05,1.52)$ \\
\hline Med-High & $1.17(0.94,1.46)$ & $1.23(0.99,1.53)$ \\
\hline High & $1.20(0.94,1.53)$ & $1.24(0.97,1.60)$ \\
\hline \multicolumn{3}{|c|}{ Polycyclic Organic Matter } \\
\hline Low & 1.00 & 1.00 \\
\hline Medium & $0.86(0.71,1.03)$ & $0.88(0.73,1.06)$ \\
\hline Med-High & $1.03(0.83,1.28)$ & $1.05(0.85,1.31)$ \\
\hline High & $0.97(0.76,1.24)$ & $1.00(0.78,1.28)$ \\
\hline \multicolumn{3}{|c|}{ Benzene and Polycyclic Organic Matter } \\
\hline \multicolumn{3}{|l|}{ Benzene } \\
\hline Low & 1.00 & 1.00 \\
\hline Medium & $1.21(1.00,1.47)$ & $1.21(1.00,1.47)$ \\
\hline Med-High & $1.08(0.87,1.34)$ & $1.09(0.87,1.35)$ \\
\hline High & $1.07(0.84,1.36)$ & $1.07(0.84,1.37)$ \\
\hline \multicolumn{3}{|c|}{ Polycyclic Organic Matter } \\
\hline Low & 1.00 & 1.00 \\
\hline Medium & $0.87(0.71,1.05)$ & $0.89(0.73,1.08)$ \\
\hline Med-High & $1.08(0.88,1.33)$ & $1.12(0.91,1.38)$ \\
\hline High & $1.05(0.82,1.33)$ & $1.10(0.86,1.39)$ \\
\hline
\end{tabular}

${ }^{a}$ Model 1 includes air pollutant exposure variables, matching variables and census tract (random effect). $N=13,420$

${ }^{\mathrm{b}}$ Model 2 includes variables from Model 1, as well as maternal age, infant birth weight (per 100 grams), infant gender and maternal race/ ethnicity. $N=13,420$

butadiene, odds of ALL remained elevated for 1,3-butadiene (medium group: $\mathrm{OR}=1.22,95 \% \mathrm{CI}$ : $1.00-1.50$; medium-high group: $\mathrm{OR}=1.28,95 \% \mathrm{CI}: 1.00-1.63$; and high exposure group: $\mathrm{OR}=1.40,95 \% \mathrm{CI}$ : 1.06-1.86). In contrast, for benzene, results were close to the null value $(\mathrm{OR}=1.07,0.95$, and 0.91 for the medium, medium-high and high exposure groups, respectively). Similarly, in the co-pollutant model with 1,3-butadiene and POM, odds remained elevated for 1,3-butadiene but not for POM. When benzene and POM were evaluated simultaneously in the same model, odds were generally elevated but diminished in magnitude relative to the results for either pollutant alone.

\section{Discussion}

We evaluated associations between residential exposures to air toxics, namely, benzene, 1,3-butadiene and POM, and ALL in children diagnosed under age 5 years in Texas from 1995 to 2011. Texas provided an unique study area to assess health effects associated with exposures to air toxics because of its extensive road traffic and congested roadways in and around large urban areas [39], abundant number of petrochemical plants [40], some of the largest petroleum refineries in the US and active seaports [14]. Moreover, the Texas Cancer Registry has more than a decade of cancer incidence data and this allowed for a population-based study with a large sample size. We found increased odds of early childhood ALL for 1,3-butadiene, benzene and POM when evaluated singly in separate models. However, in co-pollutant models, odds remained elevated only for exposure to 1,3-butadiene.

The Clean Air Act sets national air quality standards for 6 criteria air pollutants. Despite classification by the US EPA and WHO as human carcinogens, there are no mandated ambient air quality standards in the U.S. for benzene and 1,3-butadiene though their emissions are federally regulated [41]. The Texas Commission for Environmental Quality has suggested guidelines for long term (annual mean) levels in ambient air are $4.5 \mu \mathrm{g} / \mathrm{m}^{3}$ for benzene and $20.17 \mu \mathrm{g} / \mathrm{m}^{3}$ for 1,3-butadiene [42]. In our study, mean ambient air concentrations were well below these suggested levels for all time periods as indicated by Fig. 2 .

The International Agency for Research on Cancer (IARC) and U.S. EPA classify 1,3-butadiene as a human carcinogen based on evidence from occupational studies $[16,43,44]$. Studies on a cohort of butadiene monomer production workers from a Texaco plant in Texas, two styrene-butadiene rubber (SBR) production cohorts and overlapping studies with added follow-up time and improved exposure assessments of the aforementioned cohorts provide evidence of higher leukemia mortality among exposed workers. In these studies (with multiple exposure metrics that included intensity, length of exposure, cumulative exposure and time period when exposures occurred), relative risks appeared dosedependent [44]. Non-occupational studies involving 1,3butadiene are scant. One in Canada and another in the United Kingdom documented population-based exposures and have shown increased butadiene levels in urban areas adjacent to industrial sites [16, 45, 46]. A 
retrospective cohort of approximately 15,000 Texas students who attended a high school that was adjacent to a SBR production facility did not find an increase in deaths as compared to the general population [16].

After adjustment for benzene (and POM), we observed positive associations between 1,3-butadiene and odds of early childhood ALL [44, 47], with the strongest associations detected for children in the highest exposure group. The two previous studies that evaluated risks of childhood leukemia with outdoor air levels of 1,3-butadiene reported similar results. In an ecologic study, for children under age 19 years at diagnosis living in Texas census tracts with the highest 1,3-butadiene levels, a rate ratio of 1.32 (95 \% CI: 0.98-1.77) was detected for ALL [25]. Our results are also consistent with Heck et al. [21] who found elevated odds for ALL (OR =1.76, $95 \% \mathrm{CI}$ : 1.09-2.86) associated with 1,3-butadiene exposures throughout pregnancy.

It is suggested pediatric leukemia follows Knudson's two-stage model for carcinogenesis [48-51]. Unlike cellular origins of leukemia in adults, multipotent stem cells active in early fetal development are most likely involved in carcinogenesis [49]. In utero or early neonatal exposures to environmental contaminants can produce translocations and genetic alterations to hematopoietic stem cells which may be the first step in pathogenesis [2, 49, 50]. Experimental studies using rodent models suggest the mutagenic action of 1,3-butadiene epoxy metabolites on DNA is the mechanism inducing carcinogenicity. 1,3-butadiene is metabolically activated to produce reactive epoxides, diepoxybutane, epoxybutene and epoxybutanediol [16]. Epoxybutene formed in bone marrow cells and acting as an alkylating agent, may be an initiating step in hematopoietic carcinogenesis though diepoxybutane is also highly genotoxic and cross links with guanine in DNA bases $[44,52]$. Moreover, polymorphisms in epoxy hydrolase or glutathione transferase may mediate genotoxic effects of butadiene exposure [44].

DNA and hemoglobin adducts could be instrumental in identifying susceptible populations at greater risk from high levels of butadiene exposures [53]. Genetic toxicology studies show higher frequency of hemoglobin adducts and HPRT variant mutations by genotype of metabolic enzymes glutathione transferase and microsomal epoxide hydrolase $[44,54]$. Also, a urinary biomarker study showed quantifiable levels of 1,3-butadiene epoxide metabolites among adults with traffic-related exposures [55]. Corollary work documenting exposures to 1,3-butadiene and subsequent early genetic or non-genetic changes among young children is needed to further understand the role of this air toxic on early childhood leukemogenesis.

Ambient air contains a mixture of contaminants, particularly in areas with multiple pollution sources, which can vary geographically and over time $[53,56]$. The mixture of air toxics makes it difficult to differentiate the impacts of multiple pollutants in epidemiologic studies. Our results suggest the associations we detected in single pollutant models for benzene and POM were likely the result of confounding due to 1,3-butadiene. Other epidemiologic studies are needed to confirm our findings. However, our results are consistent with previous occupational cohort studies showing leukemia risks associated with butadiene exposures are confounded by co-pollutant exposures. Similar to our findings, Macaluso et al. showed leukemia risk associated with benzene is negated after controlling for butadiene and styrene [57]. And, analogous to our results with benzene and POM, styrene and dithiocarbamates (which are present in SBR production but not monomer production) show positive associations with leukemia in single pollutant models but not in copollutant models with butadiene [44].

Primary among the strengths of this study is the focus on early childhood ALL. In children, ALL incidence is greatest before age 5 [50]. Yet, relatively few investigations have examined exposure to air toxics in study populations of this age range [21, 24, 28, 58]. Differential patterns of risk and strength of point estimates on age stratification suggest divergent etiological pathways based on age of diagnosis [24, 58]. Children with leukemia onset under age 5 years likely represent a subpopulation with in utero or early infant exposures or an underlying biological susceptibility that increases risk of developing hematopoietic cancers $[48,50,53]$.

Additional strengths of the study include use of birth records to identify controls representative of the source population [59]. Employing a population-based study design, we were able to construct exposure estimates for our entire study population, making our study less prone to selection bias as might be the case when participants are selected based on residential proximity to existing air monitoring stations [21, 28] or participation is restricted to parents who had not moved after childbirth [27]. Further, our linkage of birth records to cancer registry data provided individual-level confounder information. These data were relatively complete for variables in our investigation and validity studies have found birth certificate data have high rates of correspondence with the same information present on medical records [60-64] or available from data gathered in epidemiologic studies $[61,65]$. Moreover, we had information on tobacco use during pregnancy, which is missing is other studies of childhood leukemia associated with air toxic exposures [20, 21, 23-26, 28, 58].

Our study limitations include use of U.S. EPA NATA modeled data serving as a surrogate for personal exposure, which is influenced by air pollutant levels in 
multiple outdoor and indoor environments and time spent in each microenvironment [66]. Lacking available personal- or area-level air pollutant measurements for a majority of census tracts in the U.S., NATA provides useful surrogate data for studies that examine health effects associated with ambient exposures. However, we note that the 1996 POM levels may be overestimated due to methods used to categorize PAH emissions from stack sources in the first NATA release [67] and that modelled values for benzene in 2002 may be moderately overestimated based on EPA assessments to monitored data [68]. In general, comparisons of monitored and modelled air pollutant levels show agreement (especially for benzene and 1,3-butadiene), although modelled estimates tend to underestimate air monitoring data [68-72]. Payne-Sturges et al. similarly reported good agreement between NATA data and personal exposures to benzene (1,3-butadiene and PAHs were not evaluated) [73].

Improvements in emissions, reporting, laboratory methods and sensor technology may also influence differences in air pollutant levels across the NATA releases. NATA data were only available for 1996, 1999, 2002 and 2005 (the recently issued data release for 2011 was not available when the study was conducted) and this may have introduced error in the exposure assessment. However, our sensitivity analysis restricting the study population to cases and controls born within one year of NATA release produced similar results as compared to the full study population and, hence, this limitation does not appear to have adversely affected study findings. Third, while we used maternal residence at birth to link to the modeled air toxics data, we lacked information about mobility during pregnancy or after birth. Nevertheless, Lupo et al. [74] found moving residences during pregnancy among Texas women did not significantly impact classification of benzene exposure. Our ability to examine disease risks by subtype or age at diagnosis was constrained by power considerations. AML and ALL likely have different causal pathways given geographic, demographic and diagnostic age differences among children and adults. Moreover, Cheng et al. found cumulative exposures to butadiene increased lymphoid neoplasms while peak exposures were associated with myeloid neoplasms [44] in an SBR occupational cohort. With sufficient AML cases in future, we could expanded our study to examine risks by histological subtype allowing the potential to determine if these findings translate to childhood leukemia risk associated with ambient residential exposures.

\section{Conclusions}

This study is among relatively few investigations that have examined risk of ALL relative to ambient exposures to benzene, 1,3-butadiene and POM among children less than 5 years. While we observed positive associations between all three air toxics and early childhood ALL in single pollutant models, our co-pollutant models suggest that the results for benzene and POM were likely confounded by 1,3-butadiene exposure. The consistent increase in ALL (approximately $25 \%$ ) associated with medium to high quartile ambient butadiene levels compared to the lowest quartile in this study suggest in utero exposure to butadiene may play a more important role than benzene in early childhood leukemia etiology. More work is needed to confirm these findings in other studies.

\section{Additional files}

Additional file 1: Figure S1. Benzene Ambient Air Levels in Texas by NATA Year. Benzene Ambient Air Levels in Texas by NATA Year. Map illustrating spatial distribution of ambient air benzene concentrations for all census tracts in Texas by NATA years included in our study. Figure S1: Benzene Ambient Air Levels in Texas by NATA year. Exposure groups: Low $\left(0-24^{\text {th }}\right.$ percentile); Medium $\left(25-49^{\text {th }}\right.$ percentile); Medium-High (50-74 ${ }^{\text {th }}$ percentile); High ( $75-100^{\text {th }}$ percentile) based on distribution among controls. Boundary lines for census tracts were removed for the Medium, Medium-High, and High groups and graduated color used instead to improve readability of maps and spatial distribution of exposure quartiles. (PDF $1808 \mathrm{~kb}$ )

Additional file 2: Figure S2. POM Ambient Air Levels in Texas by NATA Year. POM Ambient Air Levels in Texas by NATA Year. Map illustrating spatial distribution of ambient air POM concentrations for all census tracts in Texas by NATA years included in our study. Figure S2: POM Ambient Air Levels in Texas by NATA year. Exposure groups: Low (0-24 $4^{\text {th }}$ percentile); Medium $\left(25-49^{\text {th }}\right.$ percentile); Medium-High (50-74 ${ }^{\text {th }}$ percentile); High $\left(75-100^{\text {th }}\right.$ percentile) based on distribution among controls. Boundary lines for census tracts were removed for the Medium, Medium-High, and High groups and graduated color used instead to improve readability of maps and spatial distribution of exposure quartiles. (PDF $1816 \mathrm{~kb}$ )

\section{Abbreviations}

ALL: acute lymphocytic leukemia; AML: acute myeloid leukemia; ASPEN: Assessment System for Population Exposure Nationwide; Cl: confidence interval; DNA: deoxyribonucleic acid; IARC: International Agency for Research on Cancer; ICD-O-3: International Classification of Diseases for Oncology, $3^{\text {rd }}$ edition; NATA: US EPA National-Scale Air Toxics Assessment; OR: odds ratio; $\mathrm{PAH}$ : polycyclic aromatic hydrocarbons; POM: polycyclic organic matter; SBR: styrene-Butadiene rubber; SEER: surveillance, epidemiology and end results; TCR: Texas Cancer Registry; TX DSHS: Texas Department of State Health Services; U.S.: United States of America; US EPA: United States Environmental Protection Agency; WHO: World Health Organization.

\section{Acknowledgements}

Not applicable.

\section{Funding}

This study was supported by a grant from the National Cancer Institute (grant number, 5R03CA162172).

\section{Availability of data and materials}

The dataset supporting the conclusions of this article was obtained from the Texas Cancer Registry, Cancer Epidemiology and Surveillance Branch, Texas Department of State Health Services, 1100 West 49th Street, Austin, TX 78756, (512) 776-3080. Access can be granted only by the Texas Department of State Health Services Texas Cancer Registry. 


\section{Authors' contributions}

ES conceived and designed the study, supervised the analysis, drafted, reviewed and edited the manuscript. PGTL drafted, reviewed and edited the manuscript, performed data analysis, coordinated IRB and manuscript submissions. TYC performed the analysis, drafted portions of the manuscript, reviewed and edited manuscript. WC contributed to design and review of statistical analysis, reviewed manuscript. DL performed sensitivity analysis, reviewed and made recommendations to statistical analysis, reviewed manuscript. XM made recommendations to statistical analysis, reviewed and edited manuscript. All authors have read and approved the final manuscript.

\section{Competing interests}

The authors declare that they have no competing interests.

\section{Consent for publication}

Not Applicable.

\section{Ethics approval and consent to participate}

We conducted a secondary data analysis. Participants were not contacted and the need to obtain informed consent was waived. The study protocol was approved by the Institutional Review Boards at the University of Texas Health Science Center at Houston (HSC SPH \#12-0158) and the Texas Department of State Health Services (TX DSHS IRB\# 12-019).

\section{Author details}

'Department of Epidemiology, Human Genetics and Environmental Sciences, University of Texas Health Science Center at Houston School of Public Health, Houston, Texas, USA. ${ }^{2}$ Department of Biostatistics, University of Texas Health Science Center at Houston School of Public Health, Houston, Texas, USA. ${ }^{3}$ Yale University School of Public Health, New Haven, Connecticut, USA.

\section{Received: 9 November 2015 Accepted: 6 June 2016}

\section{Published online: 14 June 2016}

\section{References}

1. U.S. Cancer Statistics Working Group. United States Cancer Statistics: 19992012 Incidence and Mortality Web-based Report. [https://nccd.cdc.gov/uscs/ childhoodcancerdetailedbylCCC.aspx.] Accessed 1 March 2015.

2. Buffler PA, Kwan ML, Reynolds P, Urayama KY. Environmental and genetic risk factors for childhood leukemia: appraising the evidence. Cancer Invest. 2005;23(1):60-75.

3. Howlander N, Noone A, Krapcho M, Garshell J, Miller D, Altekruse S et al. SEER Cancer Statistics Review, 1975-2011, National Cancer Institute. 2014. Bethesda, MD: National Cancer Institute 2014 based on November 2013 SEER data submission, posted to the SEER website, April 2014 [http://seer. cancer.gov/csr/1975_2011//

4. TDSHS (Texas Department of State Health Services) Texas Cancer Registry. Texas Childhood Cancer Facts 2014. Information provided by personal communication with the Texas Cancer Registry 11 February 2015.

5. TDSHS (Texas Department of State Health Services) Texas Cancer Registry. Texas Cancer Registry Limited Use Data Files Information provided by personal communication with the Texas Cancer Registry 4 September 2010.

6. Belson $M$, Kingsley $B$, Holmes A. Risk factors for acute leukemia in children: a review. Environ Health Perspect. 2007;115(1):138-45.

7. Deschler B, Lubbert M. Acute myeloid leukemia: epidemiology and etiology. Cancer. 2006;107(9):2099-107.

8. Lo NL. Biology of childhood acute lymphoblastic leukemia. J Pediatr Hematol Oncol. 2013;35(4):245-52.

9. Puumala SE, Ross JA, Aplenc R, Spector LG. Epidemiology of childhood acute myeloid leukemia. Pediatr Blood Cancer. 2013;60(5):728-33.

10. Pyatt $D$, Hays S. A review of the potential association between childhood leukemia and benzene. Chem Biol Interact. 2010;184(1-2):151-64.

11. EPA (US Environmental Protection Agency). The original list of hazardous air pollutants. [http://www.epa.gov/ttn/atw/188polls.html.] Accessed 9 June 2013.

12. EPA (US Environmental Protection Agency). National Emission Standards for Hazardous Air Pollutants: Revision of Source Category List and Schedule for Standards Under Section 112 of the Clean Air Act. Report No.: 67 FR 6521 2012. [http://www3.epa.gov/ttn/atw/socatlst/fr12fe02.pdf]

13. EPA (US Environmental Protection Agency). About Air Toxics. [http://www3. epa.gov/ttn/atw/allabout.html.] Accessed 27 July 2015.
14. Pendleton DR. Air toxics: sources and monitoring in Texas. Environ Health Perspect. 1995;103 Suppl 6:223-8.

15. HEl (Health Effects Institute) Air Toxics Review Panel. Mobile-Source Air Toxics: A Critical Review of the Literature on Exposure and Health Effects. Report No.: 16. 2007. [http://pubs.healtheffects.org/getfile.php?u=384]

16. IARC (International Agency for Research on Cancer). 1,3-Butadiene IARC Monographs on the Evaluation of Carcinogenic Risks to Humans, vol 100F26. Lyon: WHO Press; 2012. p. 309-38.

17. IARC (International Agency for Research on Cancer). Benzene. IARC Monographs on the Evaluation of Carcinogenic Risks to Humans, vol 100F24. Lyon: WHO Press; 2012. p. 249-94.

18. EPA (Environmental Protection Agency). Polycyclic organic matter (POM). [http://www.epa.gov/ttn/atw/hlthef/polycycl.html.] Accessed 9 June 2013.

19. EPA (US Environmental Protection Agency). Notice of Source Category Listings for the Specific Pollutants (Section 112(c)(6)). [http://www.epa.gov/ ttnatw01/112c6/112c6fac.html.] Accessed 22 May 2013.

20. Crosignani P, Tittarelli A, Borgini A, Codazzi T, Rovelli A, Porro E, et al. Childhood leukemia and road traffic: A population-based case-control study. Int J Cancer. 2004;108(4):596-9.

21. Heck JE, Park AS, Qiu J, Cockburn M, Ritz B. Risk of leukemia in relation to exposure to ambient air toxics in pregnancy and early childhood. Int J Hyg Environ Health. 2014;217(6):662-8.

22. Lagorio S, Ferrante D, Ranucci A, Negri S, Sacco P, Rondelli R et al. Exposure to benzene and childhood leukaemia: a pilot case-control study. BMJ Open 2013; 3(2).

23. Raaschou-Nielsen $\mathrm{O}$, Hertel O, Thomsen BL, Olsen JH. Air Pollution from Traffic at the Residence of Children with Cancer. Am J Epidemiol. 2001. 153(5):433-43.

24. Vinceti M, Rothman KJ, Crespi CM, Sterni A, Cherubini A, Guerra L, et al. Leukemia risk in children exposed to benzene and PM10 from vehicular traffic: a case-control study in an Italian population. Eur J Epidemiol. 2012; 27(10):781-90.

25. Whitworth KW, Symanski E, Coker AL. Childhood lymphohematopoietic cancer incidence and hazardous air pollutants in southeast Texas, 19952004. Environ Health Perspect. 2008;116(11):1576-80.

26. Houot J, Marquant F, Goujon S, Faure L, Honore C, Roth MH et al. Residential Proximity to Heavy-Traffic Roads, Benzene Exposure, and Childhood Leukemia-The GEOCAP Study, 2002-2007. Am J Epidemiol. 2015; 182(8):685-693.

27. Deziel NC, Rull RP, Colt JS, Reynolds P, Whitehead TP, Gunier RB, et al. Polycyclic aromatic hydrocarbons in residential dust and risk of childhood acute lymphoblastic leukemia. Environ Res. 2014;133:388-95.

28. Heck JE, Wu J, Lombardi C, Qiu J, Meyers TJ, Wilhelm M, et al. Childhood cancer and traffic-related air pollution exposure in pregnancy and early life. Environ Health Perspect. 2013:121(11-12):1385-91.

29. EPA (US Environmental Protection Agency). National Air Toxics Assessments [www.epa.gov/nationalair-toxics-assessment.] Accessed 22 May 2013.

30. Environmental Protection Agency (US). The Four Steps of the Assessment [https://archive.epa.gov/airtoxics/nata1999/web/html/4steps99.html.] Accessed 22 May 2013

31. EPA (US Environmental Protection Agency). The ASPEN Model. [https:// archive.epa.gov/airtoxics/nata1999/web/html/aspen99.html.] Accessed 9 June 2013.

32. Environmental Protection Agency (US). Previous NATA Assessments. [https:// www.epa.gov/national-air-toxics-assessment/previous-nata-assessments.] Accessed 22 March 2016

33. Census Bureau (US). Census 2000 Poverty by Census Tracts by States. [www. census.gov/hhes/www/poverty/data/census/2000/index.html.] Accessed 16 August 2013.

34. Rothman KJ, Greenland S, Lash TL. Modern Epidemiology. 3rd ed. Philadelphia: Lippincott Williams \& Wilkins; 2008

35. Szklo M, Nieto J. Epidemiology: Beyond the Basics. 3rd ed. Burlington: Jones \& Bartlett Learning; 2007

36. Rosner B. Fundamentals of Biostatistics. 7th ed. Boston: Cengage Learning 2010

37. Dormann CF, Elith J, Bacher S, Buchmann C, Carl G, Carré G, et al. Collinearity: a review of methods to deal with it and a simulation study evaluating their performance. Ecography. 2013;36(1):27-46.

38. Kleinbaum DG, Kupper LL, Muller KE. Applied regression analysis and other multivariate analysis methods. 2nd ed. Boston: PWS-Kent Publishing; 1988. 
39. Texas Department of Transportation. 100 Congested Roadways [http://www. txdot.gov/inside-txdot/projects/100-congested-roadways.html.] Accessed 22 June 2015.

40. Texas Economic Development Corporation. Petroleum Refining and Chemical Products. [https://texaswideopenforbusiness.com/industries/ petroleum-refining-chemical-products.] Accessed 22 June 2015.

41. EPA (Environmental Protection Agency). Hazardous Air Pollutants. [http:// www.epa.gov/haps.] Accessed 4 March 2016.

42. Texas Commission on Environmental Quality. Air Monitoring Comparison Values. [http://www.tceq.state.tx.us/cgi-bin/compliance/monops/agc_amcvs. pl.] Accessed 4 March 2016.

43. EPA (US Environmental Protection Agency). 1,3-BUTADIENE. [http://www. epa.gov/ttn/atw/hlthef/butadien.html.] Accessed 29 July 2013.

44. IARC (International Agency for Research on Cancer). 1,3-Butadiene, Ethylene Oxide and Vinyl Halides (vinyl fluoride, vinyl chloride and vinyl bromide). IARC Monographs on the Evaluation of Carcinogenic Risks to Humans, vol 97. Lyon: WHO Press; 2008. p. 3-471.

45. Dollard G, Dumitrean P, Telling S, Dixon J, Derwent R. Observed trends in ambient concentrations of C 2-C 8 hydrocarbons in the United Kingdom over the period from 1993 to 2004. Atmos Environ. 2007;41(12):2559-69.

46. Canada H. Priority substances list assessment report: 1,3-Butadiene. 2000 [http://www.hc-sc.gc.ca/ewh-semt/pubs/contaminants/psl2-Isp2/1_3_ butadiene/index-eng.php].

47. EPA (Environmental Protection Agency). Health Assessment of 1,3Butadiene. Report No.: EPA/600/P-98/001 F. 2002. [http://cfpub.epa.gov/ ncea/cfm/recordisplay.cfm?deid=54499\#Download]

48. Carozza SE, Langlois PH, Miller EA, Canfield M. Are children with birth defects at higher risk of childhood cancers? Am J Epidemiol. 2012;175(12): $1217-24$.

49. Greaves MF, Wiemels J. Origins of chromosome translocations in childhood leukaemia. Nature Reviews Cancer. 2003;3(9):639-49.

50. Eden T. Aetiology of childhood leukaemia. Cancer Treat Rev. 2010;36(4):286-97.

51. Pedersen M, Wichmann J, Autrup H, Dang DA, Decordier I, Hvidberg M, et al. Increased micronuclei and bulky DNA adducts in cord blood after maternal exposures to traffic-related air pollution. Environ Res. 2009;109(8): 1012-20.

52. Lewtas J. Human exposure to complex mixtures of air pollutants. Toxicol Lett. 1994;72(1-3):163-9.

53. Möller L, Schuetzle D, Autrup H. Future research needs associated with the assessment of potential human health risks from exposure to toxic ambient air pollutants. Environ Health Perspect. 1994;102 Suppl 4:193.

54. Abdel-Rahman SZ, El-Zein RA, Ammenheuser MM, Yang Z, Stock TH, Morandi $M$, et al. Variability in human sensitivity to 1,3-butadiene: Influence of the allelic variants of the microsomal epoxide hydrolase gene. Environ Mol Mutagen. 2003;41(2):140-6.

55. Sapkota A, Halden RU, Dominici F, Groopman JD, Buckley TJ. Urinary biomarkers of 1,3-butadiene in environmental settings using liquid chromatography isotope dilution tandem mass spectrometry. Chem Biol Interact. 2006;160(1):70-9.

56. Lewtas J. Complex mixtures of air pollutants: characterizing the cancer risk of polycyclic organic matter. Environ Health Perspect. 1993;100:211-8.

57. Macaluso M, Larson R, Delzell E, Sathiakumar N, Hovinga M, Julian J, et al. Leukemia and cumulative exposure to butadiene, styrene and benzene among workers in the synthetic rubber industry. Toxicology. 1996;113(1-3):190-202.

58. Reynolds P, Von Behren J, Gunier RB, Goldberg DE, Hertz A, Smith DF. Childhood cancer incidence rates and hazardous air pollutants in California: an exploratory analysis. Environ Health Perspect. 2003;111(4):663-8.

59. Ma X, Buffler PA, Layefsky M, Does MB, Reynolds P. Control selection strategies in case-control studies of childhood diseases. Am J Epidemiol. 2004;159(10):915-21.

60. Baumeister L, Marchi K, Pearl M, Williams R, Braveman P. The validity of information on "race" and "Hispanic ethnicity" in California birth certificate data. Health Serv Res. 2000;35(4):869-83.

61. Honein MA, Paulozzi $\sqcup$, Watkins ML. Maternal smoking and birth defects: validity of birth certificate data for effect estimation. Public Health Rep. 2001;116(4):327-35.

62. Piper JM, Mitchel Jr EF, Snowden M, Hall C, Adams M, Taylor P. Validation of 1989 Tennessee birth certificates using maternal and newborn hospital records. Am J Epidemiol. 1993;137(7):758-68.
63. Roohan PJ, Josberger RE, Acar J, Dabir P, Feder HM, Gagliano PJ. Validation of birth certificate data in New York State. J Community Health. 2003;28(5): 335-46.

64. Zollinger TW, Przybylski MJ, Gamache RE. Reliability of Indiana birth certificate data compared to medical records. Ann Epidemiol. 2006;16(1):1-10.

65. Vinikoor LC, Messer LC, Laraia BA, Kaufman JS. Reliability of variables on the North Carolina birth certificate: a comparison with directly queried values from a cohort study. Paediatr Perinat Epidemiol. 2010;24(1):102-12.

66. Lee K, Parkhurst WJ, Xue J, Ozkaynak AH, Neuberg D, Spengler JD. Outdoor/ Indoor/Personal ozone exposures of children in Nashville. Tennessee J Air Waste Manag Assoc. 2004;54(3):352-9.

67. Environmental Protection Agency (US): Approach for modelling POM. In: US EPA Archived document. Enviornmental Protection Agency (US), 1999 [http://archive.epa.gov/airtoxics/nata1999/web/pdf/pomapproachjan.pdf] Accessed 3 March 2016.

68. EPA (Environmental Protection Agency). Comparison of 2002 ModelPredicted Concentrations to Monitored Data. [https://archive.epa.gov/ nata2002/web/html/compare.html.] Accessed 21 March 2016.

69. Environmental Protection Agency (US). Comparison of ASPEN Modeling System Results to Monitored Concentrations. [http://archive.epa.gov/ airtoxics/nata/web/html/mtom_pre.html.] Accessed 1 November 2010.

70. EPA (Environmental Protection Agency). Comparison of ASPEN Modeling System Results to Monitored Concentrations. [https://archive.epa.gov/ airtoxics/nata/web/html/mtom_pre.html.] Accessed 23 March 2016.

71. EPA (Environmental Protection Agency). Comparison of 1999 ModelPredicted Concentrations to Monitored Data. [https://archive.epa.gov/ airtoxics/nata1999/web/html/99compare.html.] Accessed 23 March 2016.

72. Lupo PJ, Symanski E. A comparative analysis of modeled and monitored ambient hazardous air pollutants in Texas: a novel approach using concordance correlation. J Air Waste Manag Assoc. 2009;59(11):1278-86.

73. Payne-Sturges DC, Burke TA, Breysse P, Diener-West M, Buckley TJ. Personal exposure meets risk assessment: a comparison of measured and modeled exposures and risks in an urban community. Environ Health Perspect. 2004; 112(5):589-98

74. Lupo PJ, Symanski E, Chan W, Mitchell LE, Waller DK, Canfield MA, et al. Differences in exposure assignment between conception and delivery: the impact of maternal mobility. Paediatr Perinat Epidemiol. 2010;24(2):200-8.

\section{Submit your next manuscript to BioMed Central and we will help you at every step:}

- We accept pre-submission inquiries

- Our selector tool helps you to find the most relevant journal

- We provide round the clock customer support

- Convenient online submission

- Thorough peer review

- Inclusion in PubMed and all major indexing services

- Maximum visibility for your research

Submit your manuscript at www.biomedcentral.com/submit 